\title{
Endoscopic line-attached clipping closure with laparoscopic suturing for duodenal defects involving the medial wall post-endoscopic submucosal dissection
}

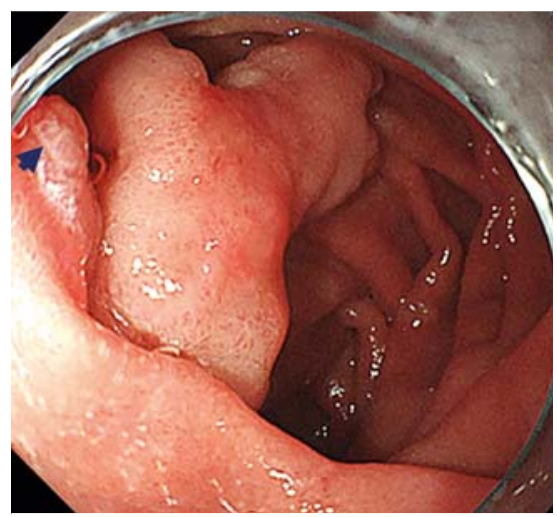

- Fig. 1 A 3-cm superficial flat tumor was laterally spread from the para-ampulla of the medial wall to the anterior wall in the second portion of the duodenum. The blue arrow indicates the ampulla.

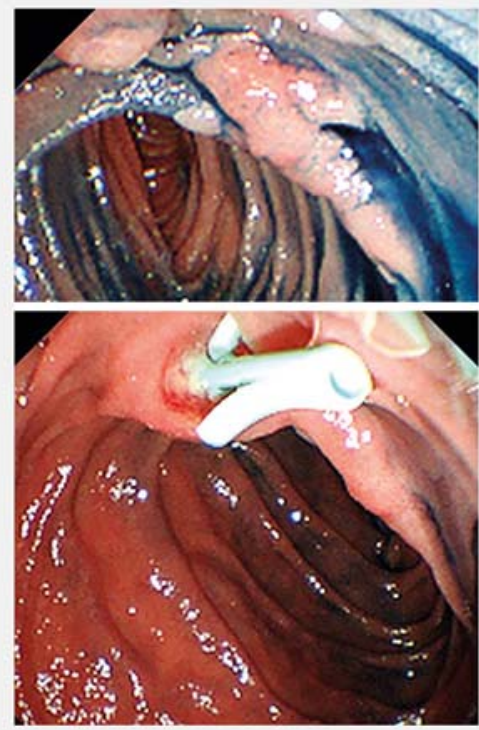

- Fig. 2 A side-view endoscopic image showing the laterally spreading tumor in the para-ampulla. An endoscopic pancreatic stent was inserted before endoscopic submucosal dissection.
Duodenal endoscopic submucosal dissection (ESD) is difficult to perform owing to a high incidence of complications, including intra/post-ESD perforation and bleeding. A complete closure of the post-ESD mucosal defect can prevent post-ESD perforation, but the success of a complete endoscopic closure depends on the size and location of the defect [1]. Although laparoscopic seromuscular suturing is the most reliable closing method [2], it cannot be used for duodenal lesions over the medial wall.

A 50-year-old man was endoscopically diagnosed with a duodenal adenoma, which was a flat, elevated, 3-cm lesion located near the ampulla and extended from the medial wall to the anterior wall of the second portion of the duodenum ( Fig.1). This lesion was judged as an indication for ESD, but it was difficult to achieve a complete closure with endoscopic clipping. Hence, duodenal ESD was planned, followed by a combined closure method including endoscopic line-attached clipping and laparoscopic suturing.

Endoscopic pancreatic stenting was performed to visualize the position of the ampulla and to prevent post-ESD pancreatitis before ESD ( $>$ Fig. 2). A duodenal adenoma was successfully resected en bloc with ESD. The post-ESD mucosal defect extended from the medial wall to the anterior wall. The anterior-wall defect was visualized with a transparent laparoscopic light, whereas no laparoscopic light was observed in the medial defect ( Fig.3). Subsequently, the anteriorwall defect was laparoscopically sutured from the serosal side, and the medialwall defect was closed with line-attached clipping. Finally, the post-ESD mucosal defect was completely closed (> Fig.4). The resected tumor was pathologically diagnosed as high-grade dysplasia ( $>$ Fig.5). No adverse events were observed after the treatment. The pancreat-

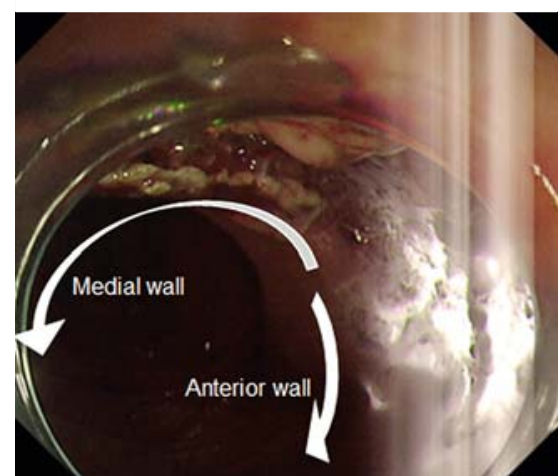

Fig. 3 The post-endoscopic submucosal dissection mucosal defect was observed to extend from the medial wall to the anterior wall of the second portion of the duodenum. The anterior site could be recognized based on an extraluminal laparoscopic light and the medial site could be recognized without a laparoscopic light.

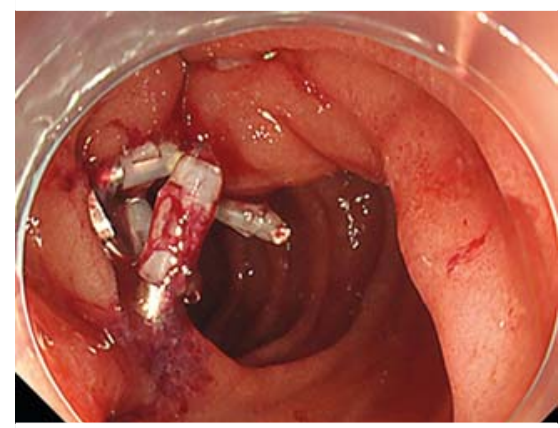

Fig. 4 Complete closure with line-attached endoscopic clipping and laparoscopic suturing.

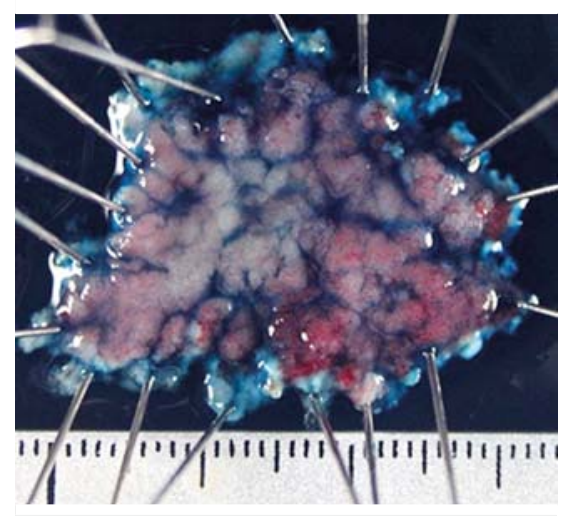

Fig. 5 The resected tumor was a $3-\mathrm{cm}$ high-grade dysplasia. 


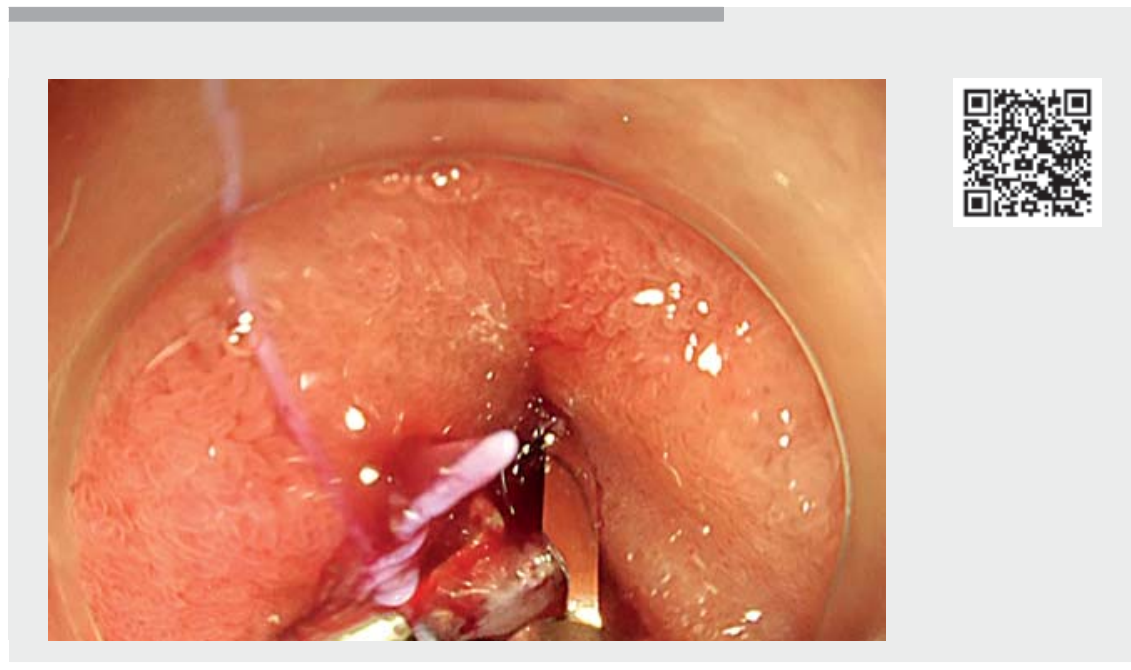

$\checkmark$ Video 1 Duodenal endoscopic submucosal dissection (ESD) followed by a complete closure of the post-ESD duodenal defects involving the medial wall.

ic stent was endoscopically retrieved 2 months later.

Endoscopic line-attached clipping closure with laparoscopic suturing is a useful closure technique for duodenal postESD defects involving the medial wall ( Video 1).

Endoscopy_UCTN_Code_TTT_1AO_2AI

Competing interests

The authors declare that they have no conflict of interest.

The authors

Takaya Shimura' ${ }^{\complement}$, Hiroyasu Iwasaki ${ }^{1}$, Tomotaka Okubo², Naomi Sugimura', Yusuke Okuda $^{1}$, Takahito Katano' ${ }^{1}$, Hiromi Kataoka ${ }^{1}$

1 Department of Gastroenterology and Metabolism, Nagoya City University Graduate School of Medical Sciences, Nagoya, Japan
2 Department of Gastroenterological Surgery, Nagoya City University Graduate School of Medical Sciences, Nagoya, Japan

\section{Corresponding author}

Takaya Shimura, MD, PhD

Department of Gastroenterology and Metabolism, Nagoya City University Graduate School of Medical Sciences, 1 Kawasumi, Mizuho-cho, Mizuho-ku, Nagoya 467-8601, Japan

Fax: +81-52-852-0952

tshimura@med.nagoya-cu.ac.jp

\section{References}

[1] Kato M, Ochiai Y, Fukuhara S et al. Clinical impact of closure of the mucosal defect after duodenal endoscopic submucosal dissection. Gastrointest Endosc 2019; 89: 8793

[2] Ichikawa D, Komatsu S, Dohi O et al. Laparoscopic and endoscopic co-operative surgery for non-ampullary duodenal tumors. World ] Gastroenterol 2016; 22: 10424-10431
Bibliography

Endoscopy 2022; 54: E528-E529

DOI 10.1055/a-1662-4651

ISSN 0013-726X

published online 25.10 .2021

(C) 2021. Thieme. All rights reserved.

Georg Thieme Verlag KG, Rüdigerstraße 14,

70469 Stuttgart, Germany

\section{ENDOSCOPY E-VIDEOS}

https://eref.thieme.de/e-videos

口回 Endoscopy E-Videos is an open access online section, 自辞: reporting on interesting cases and new techniques in gastroenterological endoscopy. All papers include a high quality video and all contributions are freely accessible online. Processing charges apply (currently EUR 375), discounts and wavers acc. to HINARI are available.

This section has its own submission website at https://mc.manuscriptcentral.com/e-videos 